\title{
ARQUEOLOGIA HISTÓRICA NO BAIXO VALE DO RIBEIRA: DOCUMENTAÇÃO TEXTUAL E MATERIAL
}

A presente nota tem por objetivo apresentar um primeiro informe a respeito do trabalho que vem sendo desenvolvido no Baixo Vale do Ribeira sobre os vestígios histórico-arqueológicos da região.'

Os dados e informações sobre a ocupação européia estão sendo obtidos através de três tipos de documento: fontes textuais, fontes orais e vestígios arqueológicos, que exigem um tratamento metodológico diferenciado.

A intenção, é claro, não foi criar intrincadas formas de abordar o objeto de trabalho, a fim de revolucionar o estudo arqueológico no Brasil. Foi, sim, proceder a uma tentativa de entendimento do processo de assentamento que vem acontecendo na região desde a chegada dos europeus no Brasil e seus reflexos na situação atual.

$\mathrm{O}$ aspecto mais importante do trabalho reside na utilização de fontes orais e textuais de maneira ativa, não apenas como "complemento" das informações arqueológicas. $\mathrm{O}$ projeto está sendo desenvolvido dentro de uma abordagem de área. Nestas condições privilegia todo um complexo e interdependente conjunto de construções, desde edifícios até intervenções mais profundas no ambiente, como obras hidraúlicas e sistemas viários.

Para tanto, foi desenvolvido levantamento de sítios arqueológicos da região (primeira etapa ao longo do Mar Pequeno e, segunda, ao longo da margem direita do Rio Ribeira - do Valo Grande até a sua Barra). O resultado foi bastante satisfatório pois, além de localizar trinta e quatro sítios arqueológicos - vinte e quatro deles históricos-, ainda foram obtidas algumas informações a respeito dos mesmos, através de antigos moradores da região.

Paralelamente, foram desenvolvidas pesquisas das fontes textuais no Arquivo do Estado de São Paulo, no Cartório de Registro Geral de Iguape e, recentemente, no Arquivo da Cúria Metropolitana. Fontes textuais secundárias também foram levantadas em diversas Instituições.

(1) Faz parte de um projeto mais amplo coordenado pela Profa. Dra. Maria Cristina Mineiro Scatamacchia.
Esta nota trata basicamente da apresentação do método de sistematização das fontes textuais primárias e sua relação com os vestígios arqueológicos encontrados, bem como do alcance das novas possibilidades vislumbradas, a partir das pesquisas preliminares.

\section{Breve abordagem histórica da região}

A história da região vem sendo escrita desde a chegada dos primeiros europeus ao Brasil. A ocorrência de lendas na região é intensa, começando com a primeira fundação, cujo local ainda não é conhecido. Existe uma história em torno do Bacharel de Cananéa que teria habitado a Barra de Icapara.

A presença dos nativos na época do descobrimento pode ser atestada pelos sítios arqueológicos de contato já estudados na área. Há notícias, fornecidas pelos cronistas do século XVI, que mostram que a região teria sido rota de entrada de expedições de reconhecimento.

A região passou a ter importância com a descoberta de ouro, no início do século XVII, abrigando a primeira Casa de Quintar Ouro da Colônia.

Seu auge aconteceu com o ciclo do arroz que gerou a maior parte das ruínas - antigos engenhos, obras hidraúlicas e viárias, localizadas até o momento. São deste tempo as histórias sobre os escravos que ainda estão bem vivas no imaginário popular. Eles insistem em chamar qualquer ruína construída com pedras de "Senzala". A presença dos índios, no entanto, parece ter sido esquecida ao longo do tempo.

A pesquisa de arqueologia histórica é inédita na região, que já tinha sido objeto de atenção com referência a outros períodos de ocupação. ${ }^{2}$

(2) A região passou por diversos tipos de "exploração arqueológica". Desde a exploração do naturalista alemão Krone até excursões promovidas por curiosos. Os Profs. Drs. Dorath Pinto Uchôa e Caio Del Rio Garcia também procederam a levantamentos dos Sambaquis nas décadas de 60 e 70. Desde a década de 80, a Profa. Maria Cristina Mineiro Scatamacchia vem desenvolvendo pesquisas na área. 
O estudo do complexo constituído por essas ruínas e seu contexto de utilização mostra-se, assim, útil do ponto de vista do exercício acadêmico, resgatando informações a respeito das técnicas utilizadas e das respostas adaptativas ao meio realizada pela antiga população, trazendo à luz dados importantes, a fim de que se proceda a um melhor conhecimento da região, possibilitando, entre outras coisas, uma utilização organizada e racional do potencial turístico da área em pauta.

\section{Arquivo do Estado de São Paulo}

Dos documentos pesquisados na referida instituição, os que trazem maior quantidade de dados relevantes são aqueles reunidos sob o título de "Requerimentos e Ordenanças", "Ofícios" e "Ofícios Diversos", todos de origem oficial ligados à administração da Colônia e mais tarde do Império; verificou-se também a existência dos "Documentos Interessantes" e "Boletim"que trazem documentos de diversos tipos selecionados por antigos funcionários do Arquivo; já as "Sesmarias" e os "Inventários e Testamentos" trazem informações de documentos mais antigos, só preservadas graças ao fato de terem sido publicadas (a partir do início deste século).

Grande parte dos documentos referem-se a povoações incipientes dos arredores da atual cidade de Iguape e em direção ao interior; a maioria deles foi produzida nos séculos XVIII e XIX. Quanto aos primeiros séculos de colonização, a maior parte trata de sesmarias (ou datas de terra), inventários e testamentos.

A fim de organizar as informações coletadas, foi elaborada uma ficha onde constam informações sobre a localização e tipo do documento, autor, período, tipo de estrutura descrita ou mencionada, desenho da estrutura, compilação e número do catálogo de informação.

O grande volume de documentação textual pesquisado no Arquivo do Estado de São Paulo foi dividido em dois grandes grupos, a fim de facilitar o trabalho de resgate de informações de interesse arqueológico:

1. Assuntos gerais - são todos os documentos que oferecem algum tipo de informação não relacionada diretamente à cultura material, mas sobre as atividades desenvolvidas na região estudada. São aqueles documentos que os historiadores utilizam para tentar reconstruir a realidade de outras épocas, privilegiando questões mais ligadas ao mundo das idéias, do cotidiano, etc.

Além de contribuir para traçar um panorama da evolução do processo de ocupação da área, sob um ponto de vista mais amplo, esta documentação pode fornecer dados indiretos sobre a localização dos vestígios materiais que as sociedades antigas produziram.

Esta categoria engloba temas abrangentes, tais como mineração, situação dos indígenas, dos escravos, vigilância dos portos e invasões de piratas, naufrágios, exploração de madeiras, etc. (ver Quadro I).

2. Estruturas - esta categoria trata de informações relacionadas diretamente às estruturas construídas pelo homem e que modificam, em diferentes graus de grandeza, o meio ambiente (ecofato). Trata-se de sistemas viários, sistemas hídricos, bens particulares e obras públicas. Os temas mais comuns referem-se ao destino de edificações, tais como a Casa de Quintar Ouro e da antiga Matriz de Iguape, às fundações de povoados, à situação dos engenhos, à abertura de estradas, à construção ou manutenção de canalizações, pontes, valos, furados, portos, etc. (Quadro II ) e à distribuição ou redistribuição de terras.

O Quadro III traz o nome dos sítios localizados, as unidades de observação e o material existente em cada um. Posteriormente, uma nova coluna será incluída, trazendo a compilação e referência da documentação textual correspondente a cada sítio.

Assim, a proposta é trabalhar sistematicamente com as duas fontes de documentos, visando caracterizar a ocupação histórica da região. 
QUADRO I

\begin{tabular}{|c|c|c|c|}
\hline \multicolumn{4}{|c|}{ Assuntos Gerais } \\
\hline Tipo dedocumentos & Data & Assunto & Obs. \\
\hline $\begin{array}{l}\text { Ordenanças e } \\
\text { Requerimentos }\end{array}$ & $08 / 07 / 1722$ & Necessidade de defesa da Barra graças à presença de piratas. & \\
\hline $\begin{array}{l}\text { Ordenanças e } \\
\text { Requerimentos }\end{array}$ & $01 / 08 / 1722$ & Fortaleza - necessidade de defesa da Vila & \\
\hline $\begin{array}{l}\text { Ordenanças e } \\
\text { Requerimentos }\end{array}$ & $23 / 04 / 1817$ & $\begin{array}{l}\text { Entrada e saída de embarcações sem vigilância na Barra de } \\
\text { Icapara. }\end{array}$ & \\
\hline $\begin{array}{l}\text { Ordenanças e } \\
\text { Requerimentos }\end{array}$ & $30 / 04 / 1809$ & $\begin{array}{l}\text { Sobre a fortaleza da Barra de Cananéa e a necessidade de defesa } \\
\text { na Barra do Ribeira. }\end{array}$ & \\
\hline Carta Régia & $08 / 07 / 1726$ & $\begin{array}{l}\text { Perigo de invasões piratas em Iguape e Cananéa (falta de } \\
\text { fortalezas). }\end{array}$ & * Docs. Ints. \\
\hline $\begin{array}{l}\text { Ordenanças e } \\
\text { Requerimentos }\end{array}$ & 1829 & Vigia da vila. & \\
\hline Carta Régia & & Chegada de dois padres para levantarem plantas e mapas. & * Docs. Ints. \\
\hline Ofício & $08 / 10 / 1855$ & Remetendo mapas de exploração indígena. & \\
\hline $\begin{array}{l}\text { Ofícios } \\
\text { Diversos }\end{array}$ & $186 ?$ & $\begin{array}{l}\text { Informa a efetuação de uma planta provisória da Barra de } \\
\text { Icapara. }\end{array}$ & \\
\hline Ofício & $08 / 03 / 1853$ & Invasões dos índios Botocudos em Itariry. & \\
\hline Ofício & $09 / 06 / 1848$ & $\begin{array}{l}\text { Arrecadação da "peça" da Barra de Icapara; forte na Barra de } \\
\text { Cananéa. }\end{array}$ & \\
\hline & $05 / 12 / 1765$ & Fundação de povoação na Ribeira de Sabaúma. & $*$ Docs. Ints. \\
\hline
\end{tabular}

* Documentos publicados na coleção Documentos Interessantes no volume 18, pp. 230, 261 e volume 65, p. 29, respectivamente. 


\section{QUADRO II}

\begin{tabular}{|c|c|c|c|}
\hline \multicolumn{4}{|c|}{ Estruturas } \\
\hline Tipo de documento & Data & Estrutura mencionada & Obs. \\
\hline Pedido de terras & $25 / 06 / 1684$ & Minas de prata de Parnagoá (gentios de diversas nações) & \\
\hline Requerimentos & $01 / 01 / 1726$ & Casa de quintar ouro & \\
\hline Ofício & $06 / 02 / 1856$ & Estradas de serra & \\
\hline Ofício & $02 / 03 / 1852$ & Envia a relação de bens pertencentes à fabrica desta cidade & \\
\hline Carta & & Serviço de paradas no Porto do Una & *Docs.Ints. \\
\hline Requerimento & $15 / 03 / 1734$ & Casa de oficina de iguape & \\
\hline Requerimento & $19 / 02 / 1817$ & Casa de fundição de ouro & \\
\hline Ofício & $06 / 12 / 1841$ & Engenho de serra & \\
\hline Ofício & $20 / 03 / 1852$ & $\begin{array}{l}\text { Comunica a inexistência de fábricas em Iguape, apenas } \\
\text { alguns engenhos de arroz, de moer cana e socar café }\end{array}$ & \\
\hline Ofício & $23 / 03 / 1852$ & Mapa demonstrativo das fábricas de arroz e aguardente & \\
\hline Ofício & $04 / 11 / 1854$ & Informações a respeito das obras públicas de iguape & \\
\hline Ofício & $08 / 09 / 1858$ & Demolição da antiga Igreja Matriz de Iguape & \\
\hline Ofício & $08 / 10 / 1866$ & Canalização das águas do Morro do Senhor & \\
\hline Ofício & $10 / 10 / 1873$ & Canalização das vertentes do Morro do Senhor & liberação \\
\hline Ofício & $13 / 03 / 1876$ & Chafariz & \\
\hline
\end{tabular}

* Documentos Interessantes, volume 58, p. 349. 


\section{QUADRO III}

\begin{tabular}{|c|c|c|c|}
\hline \multicolumn{4}{|c|}{ Sítios Históricos Localizados } \\
\hline No. & Nome do sítio & Unidade de observação & Material existente \\
\hline 3 & Sítio do Júnior & barragens e blocos de pedra & \\
\hline 24 & Loteamento I & muros e blocos de conchas & conchas e telhas \\
\hline 26 & Marinheiro & vestígios arquitetônicos & faiança, vidros e telhas \\
\hline 25 & Haroldo Rollo & & faiança, cerâmicas, telhas e conchas \\
\hline 19 & Abricó & vestígios arquitetônicos & faiança e cerâmica \\
\hline 7 & Valdir & muro de pedra & , \\
\hline 15 & Itaguá & $\begin{array}{l}\text { duas construções, aterro de proteção e direcionamento de } \\
\text { água, barragem para açude }\end{array}$ & $\begin{array}{l}\text { faiança, cerâmica, telhas, metais, } \\
\text { madeira e vidro }\end{array}$ \\
\hline 8 & Sta. Therezinha & escada esculpida em rocha & duas lâminas de machado \\
\hline 17 & Lagoinha & estruturas arquitetônicas, forno e barragem & faiança \\
\hline 16 & Bocava & estruturas arquitetônicas e vestígios conchíferos & faiança e conchas \\
\hline 29 & Sítio do Lauro & estruturas arquitetônicas & \\
\hline 28 & Sítio do Dionísio & pilares, blocos de pedra e forno & faiança, telhas, cerâmicas e vidro \\
\hline 34 & Sítio do Forno & forno de pedra & \\
\hline 35 & Senzala & edifício e barragem & \\
\hline 30 & Sítio do Dito & estruturas arquitetônicas & \\
\hline 48 & Quatro Colunas & quatro colunas e muro de alvenaria & \\
\hline 36 & Porto Geande & & \\
\hline 38 & Santa Cruz & estruturas arquitetônicas & \\
\hline 39 & Boa Vista & estruturas arquitetônicas & \\
\hline 41 & Casarão & estruturas arquitetônicas, canalizações e barragem & \\
\hline 43 & Boiquara & estruturas arquitetônicas e valas & faiança, telhas e metais \\
\hline 44 & Três Barras & uma parede e três pilares & \\
\hline 06 & Tapari & alicerces & fechadura de ferro \\
\hline 47 & Porcina & estruturas arquitetônicas & \\
\hline
\end{tabular}

Recebido para publicação em 16 de dezembro de 1996. 